\title{
Established diet-induced obesity in female rats leads to offspring hyperphagia, adiposity and insulin resistance
}

\author{
P. Nivoit • C. Morens • F. A. Van Assche • E. Jansen • \\ L. Poston • C. Remacle • B. Reusens
}

Received: 8 December 2008 / Accepted: 29 January 2009/Published online: 14 March 2009

(C) Springer-Verlag 2009

\begin{abstract}
Aims/hypothesis Accumulating evidence suggests that maternal obesity may increase the risk of metabolic disease in the offspring. We investigated the effects of established maternal diet-induced obesity on male and female offspring appetite, glucose homeostasis and body composition in rats.

Methods Female Wistar rats were fed either a standard chow (3\% fat, $7 \%$ sugar $[\mathrm{wt} / \mathrm{wt}]$ ) or a palatable obesogenic diet (11\% fat, $43 \%$ sugar [wt $/ w t])$ for 8 weeks before mating and throughout pregnancy and lactation. Male and female offspring of control and obese dams were weaned on to standard chow and assessed until 12 months of age.

Results At mating, obese dams were heavier than control with associated hyperglycaemia and hyperinsulinaemia. Male and female offspring of obese dams were hyperphagic $(p<0.0001)$ and heavier than control $(p<0.0001)$ until 12 months of age. NEFA were raised at 2 months but not at 12 months. At
\end{abstract}

P. Nivoit · C. Morens · F. A. Van Assche

Department of Developmental Biology,

Katholieke Universiteit Leuven, Faculty of Medicine,

Leuven, Belgium

P. Nivoit $\cdot$ C. Morens $\cdot$ C. Remacle $\cdot$ B. Reusens $(\square)$

Département de Biologie, Unité de Biologie Animale,

Laboratoire de Biologie Cellulaire, Bâtiment Carnoy,

Université Catholique de Louvain,

Place Croix du Sud 4-5,

B-1348 Louvain-la-Neuve, Belgium

e-mail: brigitte.reusens@uclouvain.be

E. Jansen

National Institute for Public Health and the Environment,

Bilthoven, the Netherlands

L. Poston

Division of Reproduction and Endocrinology,

King's College London,

London, UK
3 months, OGTT showed more pronounced alteration of glucose homeostasis in male than in female offspring of obese animals. Euglycaemic-hyperinsulinaemic clamps performed at 8 to 9 months in female and 10 to 11 months in male offspring revealed insulin resistance in male offspring of obese dams ( $p<0.05$ compared with control). Body compositional analysis at 12 months also showed increased fat pad weights in male and female offspring of obese animals.

Conclusions/interpretation Diet-induced obesity in female rats leads to a state of insulin resistance in male offspring, associated with development of obesity and increased adiposity. An increase in food intake may play a role.

Keywords Appetite - Developmental programming . Insulin resistance $\cdot$ Metabolic syndrome - Obesity .

Pregnancy $\cdot$ Rat

\section{Abbreviation \\ GIR Glucose infusion rate}

\section{Introduction}

The metabolic syndrome is defined as a cluster of metabolic abnormalities [1] centred on obesity in association with insulin resistance, dyslipidaemia and hypertension, which together predispose an individual to diabetes and cardiovascular disease [2]. With the worldwide explosion of overweight and obesity in industrialised countries, metabolic syndrome has reached epidemic proportions, with approximately one-third of the population in the USA and Europe being affected [3]. Metabolic syndrome in children and adolescents in Western countries is also increasing, mainly due to the concomitant epidemic of overweight and obesity [4]. While the major causal factor is considered to 
be changes in lifestyle with poor physical activity and abundance of high-energy foods [5], evidence from animal and human studies now implicates events in the earliest stages of life, suggesting that aberrations in intra-uterine environment can 'program' metabolic syndrome in the offspring in later life [3, 6-8]. The evidence includes studies in human cohorts, which have suggested that maternal obesity is a risk factor for development of childhood metabolic syndrome or obesity [9-11]. Children of obese mothers also have increased risk of higher BMI in adult life [12]. While a shared post-natal environment and genetic susceptibility are likely contributors [13], the greater influence of maternal than paternal BMI on childhood BMI reported in some cohort studies may indicate an independent influence of the intrauterine environment on offspring adiposity [14]. Maternal gestational diabetes, which is strongly associated with maternal obesity, has also been associated with offspring childhood obesity [15]. Together, the studies cited have led to development of the 'fetal overnutrition hypothesis'.

Animal studies addressing this hypothesis avoid the influences of genetic traits and control for postnatal environmental influences. Studies from our laboratories and others have shown that a maternal diet rich in animal fat during gestation and lactation leads to the development of an offspring phenotype with characteristics of the metabolic syndrome even when offspring are reared on a normal diet [16-20]. However, these dietary manipulations were made only during the short period of gestation and lactation and rodents fed a diet rich in fat alone are generally resistant to the development of obesity [16].

In this study we investigated the offspring of Wistar rats in which obesity was induced by feeding a highly palatable diet enriched in fat and simple sugars from weaning throughout adult life and pregnancy. After 2 months on the diet, the animals were mated and the experimental diets maintained throughout pregnancy and lactation. All offspring were weaned on to a standard chow diet. In the offspring insulin resistance was assessed in both sexes when young and at adulthood using OGTT and euglycaemichyperinsulinaemic clamp. Offspring body composition, food intake, relevant plasma analytes and pancreatic insulin content were also determined.

\section{Methods}

Animals and diets Virgin female Wistar rats aged 21 days (Janvier, Le Genest Saint Isle, France) (body weight: $50 \pm$ $1.3 \mathrm{~g})$ were housed individually with free access to a control standard chow diet (7\% simple sugars, 50\% polysaccharide, $3 \%$ fat, $15 \%$ protein $[\mathrm{wt} / \mathrm{wt}$ ], energy $14.64 \mathrm{~kJ} / \mathrm{g} \mathrm{RM} 3$; SDS, Witham, UK) or a highly palatable obesogenic diet enriched in lard and simple sugars $(10 \%$ simple sugars, $29 \%$ polysaccharide, $23 \%$ fat $[17 \%$ animal lard], 23\% protein [wt/wt], energy $18.83 \mathrm{~kJ} / \mathrm{g}$ ) (RM AFE $45 \%$ FAT $16 \%$ SUC; SDS), and supplemented by free access to sweetened condensed milk (approx 55\% simple sugars, $8 \%$ fat, $8 \%$ protein [wt/wt], energy $16.736 \mathrm{~kJ} / \mathrm{g}$; Nestlé, Brussels, Belgium) diluted $(1: 1, \mathrm{wt} / \mathrm{wt})$ in tap water. All animals were housed under standard conditions (light on 07:00-21:00 hours; temperature $20 \pm 2^{\circ} \mathrm{C}$; humidity $50 \pm 10 \%$ ) with free access to water.

The animals were fed the control $(n=14)$ or the obese diet $(n=16)$ for 60 days prior to mating, and during gestation ( 21 days) and lactation (21 days). Food intake and body weight were assessed three times a week until mating and daily during gestation/lactation by weighing the food and condensed milk consumed.

Females were allowed to deliver spontaneously. Within $24 \mathrm{~h}$ of delivery the litter size was assessed, pups weighed and sexed, and litters culled to eight pups (four males and four females where possible). After sexing at birth, pups were not sexed again until weaning to avoid disturbance of the litter. Pups were weighed daily until weaning at 21 days. At weaning, all pups were removed from dams, housed individually and fed the control diet. Body weight and food intake were assessed three times a week.

Rats were bred according to Belgian regulations on animal welfare. The study protocol was approved by the animal use Ethical Committee of the Université catholique de Louvain.

Blood sampling and analysis of plasma variables (dams and offspring) After 2 months on the diet and prior to mating, dams were fasted overnight and tail vein blood samples collected into ice-cold heparinised tubes. The same protocol was used with non-fasted dams at gestational days 10 to 11 and overnight-fasted offspring of 2 and 12 months of age. Plasma was separated immediately after sampling by centrifugation $\left(8,000 \times \mathrm{g}, 10 \mathrm{~min}, 4^{\circ} \mathrm{C}\right)$ and stored at $-80^{\circ} \mathrm{C}$. All plasma analyses were performed at the RIVM (Bilthoven, the Netherlands) on an autoanalyser (Hitachi 912; Roche Diagnostics, Almere, the Netherlands) using the following commercial kits: Gluco-Quant/HK, Triglycerides-GPO-PAP, Cholesterol-CHOD-PAP (Roche Diagnostics, Brussels, Belgium); NEFA-C (Wako Chemicals, Neuss, Germany); rat insulin ELISA kit (Mercodia, Upsala, Sweden); and rat leptin ELISA kit (Biovendor, Modrice, Czech Republic).

OGTT (offspring) Insulinaemic and glycaemic responses to an OGTT were determined in 3-month-old male and female offspring (four males, four females per litter) after an overnight fast according to Merezak et al. [21]. After collection of a basal blood sample, $0.7 \mathrm{ml} / 100 \mathrm{~g}$ body weight of a $50 \%$ glucose solution (wt/vol., $2.78 \mathrm{~mol} / \mathrm{l}$ ) was 
administered by gavage. Tail venous blood samples were collected in ice-cold heparinised tubes at 15, 30, 60, 120 and $150 \mathrm{~min}$ to measure glucose and insulin. Glucose homeostasis was assessed by calculating the AUC of glucose and insulin.

Euglycaemic-hyperinsulinaemic clamp (offspring) Euglycaemic-hyperinsulinaemic clamps were carried out according to Perrin et al. [22], but in awake and semi-restrained animals. Females (one per litter) were studied at 8 to 9 months and males (one per litter) at 10 to 11 months. A polyethylene catheter was inserted into the right jugular vein under xylazine/ketamine anaesthesia, externalised on top of the skull and secured with dental cement. Animals were injected with finadyne $(1 \mathrm{~g} / \mathrm{kg}$ body weight; ScheringPlough, Maarssen, the Netherlands) for analgesia following surgery. The jugular catheter was used for intravenous infusion and blood samples were taken from the tail vein. Clamps were conducted at least 7 days after surgery to allow recovery from surgical stress.

Overnight-fasted rats were infused $\left(6 \mathrm{mU} \mathrm{kg}{ }^{-1} \mathrm{~min}^{-1}\right)$ with human neutral insulin (Actrapid HM, $100 \mathrm{U} / \mathrm{ml}$; Novo Industries, Copenhagen, Denmark) diluted in saline. Blood glucose was maintained at the basal level $(6 \mathrm{mmol} / \mathrm{l})$ through adjusted perfusion of glucose solution. Blood samples $(25 \mu \mathrm{l})$ were collected at 5 min intervals for measurement of plasma glucose (Glucose Analyser II; Beckman) and a $100 \mu 1$ sample was taken at baseline and during euglycaemia for insulin measurement. Total blood volume removed during the whole clamp experiment was equal to $850 \mu 1$ and replaced by saline. The glucose infusion rate (GIR), a measure of whole-body glucose utilisation, was calculated as the amount of glucose perfused during a $1 \mathrm{~h}$ period of steady-state glycaemia and expressed as mmol glucose $\mathrm{kg}^{-1} \mathrm{~min}^{-1}$.

Body composition (offspring) At 12 months of age, offspring (one of each sex per litter) were killed and the pancreas, adrenals, liver, heart, kidneys, brain, soleus muscle and fat pads (mesenteric, perirenal, perigonadal, subcutaneous) weighed and stored at $-80^{\circ} \mathrm{C}$.

Pancreatic insulin content (offspring) At death by killing (12 months of age, one animal of each sex per litter), approximately 100 to $200 \mathrm{mg}$ of the pancreas (splenic part) was homogenised in acid ethanol. Insulin content was determined (ELISA kit, Mercodia) and expressed as pmol insulin/mg tissue weight.

Statistical analysis Data are expressed as means \pm SEM, male and female rats were analysed separately. Betweengroup comparisons of body weight, food intake, OGTT and euglycaemic-hyperinsulinaemic clamp were undertaken by two-way ANOVA followed by the Bonferroni post-hoc test.
Between-group comparisons of plasma variables, pancreatic insulin content and body composition were made using Student's $t$ test. The non-parametric Mann-Whitney test was used when data were not normally distributed according to the Kolmogorov-Smirnov test. A value of $p<0.05$ was considered statistically significant. Data were analysed using GraphPad Prism (GraphPad Software, San Diego, CA, USA). In all cases, $n$ refers to the number of litters in each group. In all experiments (except the clamps) more than one animal of each sex from each litter was studied. To avoid sibling bias, data from male or female littermates were averaged to provide one data point for each sex for each litter.

\section{Results}

Dams: food intake, growth curves and plasma variables at 80 days of age Female rats fed the obese diet gained more weight than control females (Fig. 1 a). This was associated with raised energy intake (obese $400.1 \pm 5.9 \mathrm{~kJ} /$ day, days 20 to 60 , compared with control $252.7 \pm 1.3 \mathrm{~kJ} / \mathrm{day} ; p<0.001$ ) (Fig. 1 c). After 60 days on the diet, fasting plasma concentrations of glucose, insulin and leptin were significantly increased in obese compared with control females $(p<0.05)$ (Table 1). Lipids remained unaffected by the diet.
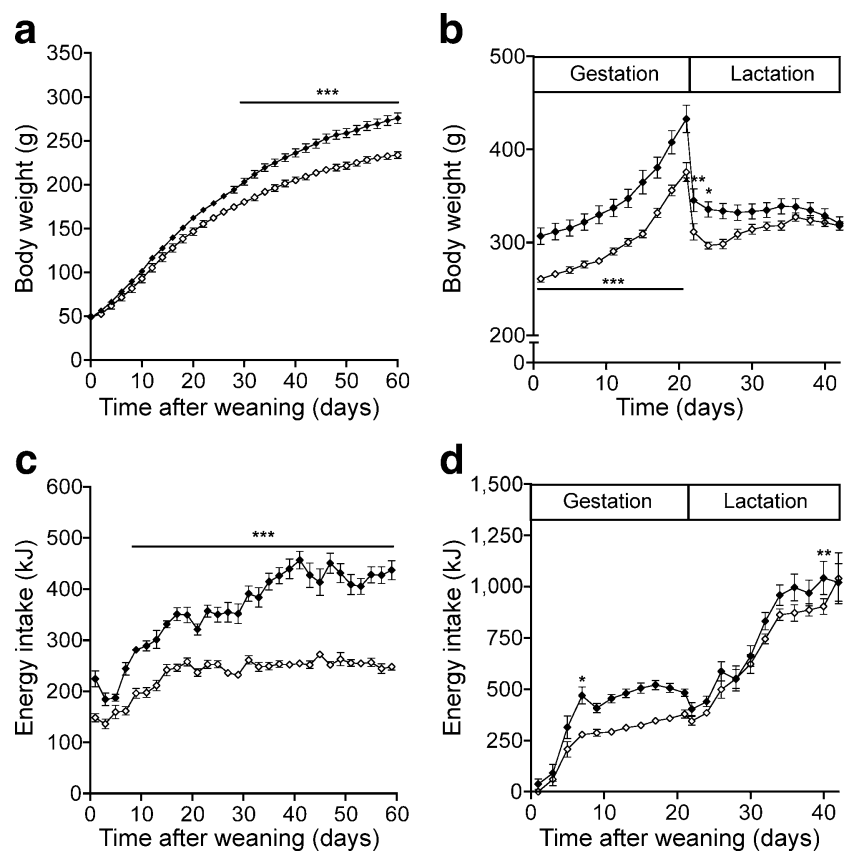

Fig. 1 Growth curves (a) and average daily energy intake (c) of female Wistar rats (dams) weaned on to control (white diamonds, $n=$ 14) or obesogenic (black diamonds, $n=16$ ) diets for 60 days. b, d Curves as above (a, c) during lactation and gestation respectively. Results are expressed as mean \pm SEM. $p<0.0001$ by ANOVA (a-d); ${ }^{*} p<0.05,{ }^{* *} p<0.01,{ }^{* * *} p<0.001$ vs control (post hoc test) 
Table 1 Plasma variables measured in female rats on experimental diet as indicated

\begin{tabular}{|c|c|c|c|c|c|c|}
\hline \multirow[t]{2}{*}{ Variable } & \multicolumn{3}{|c|}{ Dams at day 60 after weaning (fasting) } & \multicolumn{3}{|c|}{ Dams at days $10-11$ of gestation (non-fasting) } \\
\hline & Control $(n=6)$ & Obese $(n=9)$ & Diet effect $p$ value & Control $(n=5)$ & Obese $(n=9)$ & Diet effect $p$ value \\
\hline Glucose $(\mathrm{mmol} / \mathrm{l})$ & $5.5 \pm 0.2$ & $6.3 \pm 0.2$ & 0.0195 & $5.2 \pm 0.1$ & $5.9 \pm 0.2$ & 0.047 \\
\hline Insulin $(\mathrm{pmol} / \mathrm{l})$ & $8.68 \pm 3.5$ & $79.9 \pm 19.1$ & 0.0097 & $158.0 \pm 24.3$ & $340.3 \pm 46.9$ & 0.019 \\
\hline Triacylglycerol (mmol/l) & $0.70 \pm 0.08$ & $0.55 \pm 0.04$ & NS & $1.21 \pm 0.22$ & $0.77 \pm 0.12$ & NS \\
\hline NEFA $(\mathrm{mmol} / \mathrm{l})$ & $0.95 \pm 0.07$ & $0.74 \pm 0.07$ & $(0.0584)$ & $0.79 \pm 0.11$ & $0.83 \pm 0.07$ & NS \\
\hline Total cholesterol (mmol/1) & $1.26 \pm 0.08$ & $1.17 \pm 0.06$ & NS & $0.93 \pm 0.07$ & $0.79 \pm 0.07$ & NS \\
\hline Leptin (pg/ml) & $861 \pm 231$ & $3,169 \pm 381$ & 0.0005 & $2,480 \pm 321$ & $6,899 \pm 633$ & 0.0003 \\
\hline
\end{tabular}

Values are expressed as means \pm SEM

$p$ values in parentheses almost reach significance

Dams: food intake, growth curves, plasma variables during gestation and lactation At mating, obese females weighed more than control females $(303 \pm 9 \mathrm{~g}$ vs $258 \pm 3 \mathrm{~g}, p<0.001)$. During gestation, body weight of both obese and control dams increased similarly and body weight of obese females remained significantly higher than control. The same observation was made for food intake. A few days after delivery, no significant difference in body weight and food intake between obese and control females was observed (Fig. 1).

Table 1 shows plasma variables at days 10 to 11 of gestation. Plasma glucose, insulin and leptin were significantly increased in obese compared with control animals $(p<0.05)$. Lipids remained unaffected by the diet.

Offspring: birthweight, litter size and growth curves during lactation Litter size of obese pregnancies was increased (obese $14.5 \pm 0.7$ pups, $n=15$, vs control $10.6 \pm 0.6$ pups, $n=15, p<0.001)$ and although litter mass was also higher (obese $90.3 \pm 4.0 \mathrm{~g}, n=15$, vs control $73.7 \pm 3.0 \mathrm{~g}, n=15$, $p<0.01$ ), within each litter offspring of obese dams had lower birthweights than control $(6.25 \pm 0.11 \mathrm{~g}, n=15$, vs $6.88 \pm 0.12 \mathrm{~g}, n=15, p<0.001)$. The litter female:male sex ratio, an imbalance of which could contribute to litter birthweight differences, was not significantly different between groups (female:male obese $1.5 \pm 0.4, n=15$, vs control $1.3 \pm 0.2, n=15)$.

After litter size was reduced to eight pups in all litters (four of each sex), individual pup weights were assessed daily until weaning but animals were not sexed at weighing until weaning. Progressively, pups of obese dams became heavier than control (ANOVA $p<0.001$ ). Post hoc analysis revealed no difference in pup weights until 12 days of age, when weights diverged significantly until weaning at day 21 (64.5 $\pm 2.2 \mathrm{~g}, n=13$, vs $55.7 \pm 1.3 \mathrm{~g}, n=15, p<0.001)$ (Fig. 2).

Offspring: post-weaning food intake and growth curves By 4 weeks of age, i.e. 1 week after weaning, there was no difference in bodyweight between male and female offspring of obese and control dams. As the animals matured, male offspring of obese dams again became heavier than control (ANOVA, $p<0.0001$ ) and demonstrated hyperphagia as shown by an increase in weekly food intake (ANOVA, $p<0.0001)$. Differences were less pronounced in female offspring of obese dams, although both weight and food intake were greater than control offspring $(p<0.0001)$. In contrast to male offspring, body weight and average daily food intake curves of female offspring from obese and control groups converged at week 52 (Fig. 3).

Offspring: plasma variables at 2 and 12 months of age At 2 months of age, the plasma concentration of NEFA was significantly increased in male and female animals of obese dams compared with control $(p<0.05)$ (Table 2$)$. In males alone, the leptin concentration was raised in the same group $(p<0.05)$.

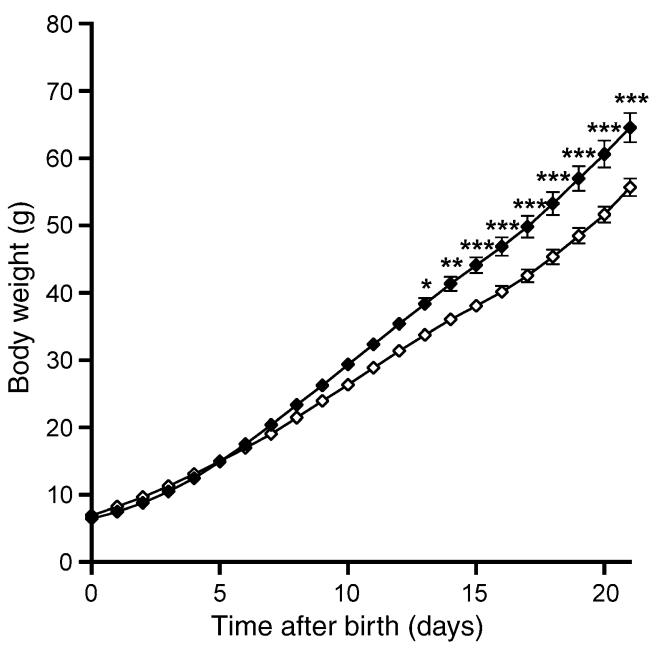

Fig. 2 Growth curves of the pups (male and female) from dams fed the control (white diamonds, $n=15$ ) or obesogenic (black diamonds, $n=13$ ) diets during lactation. Results are expressed as mean \pm SEM. $p=0.0015$ by ANOVA; $* p<0.05, * * p<0.01, * * * p<0.001$ vs control (post hoc test) 

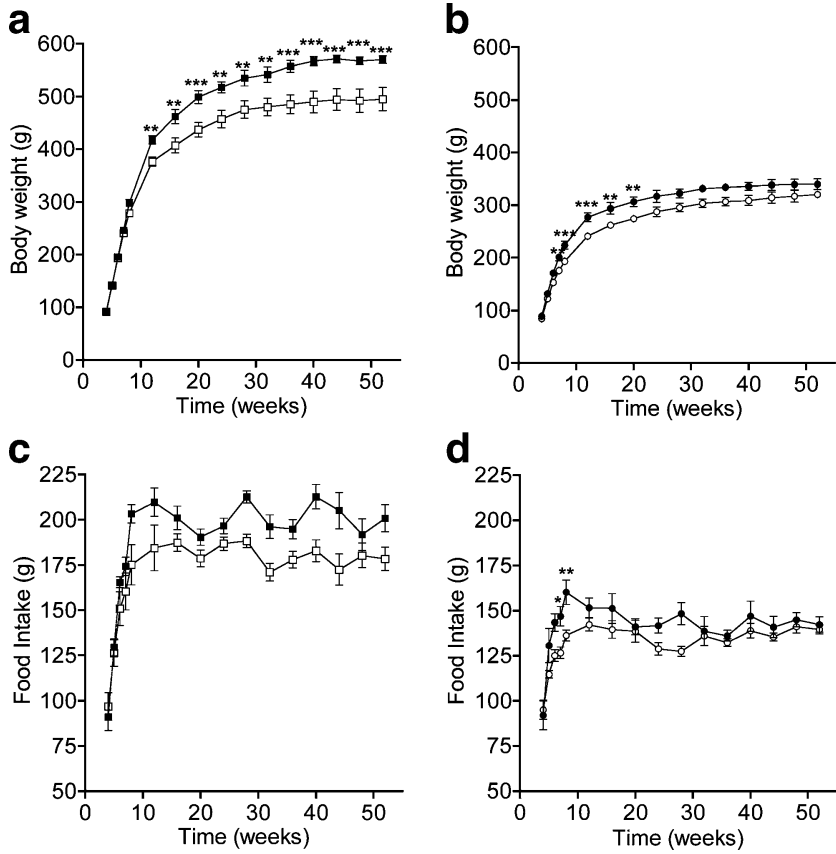

Fig. 3 Body weight (a, b) and average weekly food intake (c, d) of male (a, c) offspring (control: white squares, $n=15$; obese: black squares, $n=10)$ and female (b, d) offspring (control: white circles, $n=$ 15; obese: black circles, $n=8$ ) fed standard chow diet from weaning. Results are expressed as mean \pm SEM. $p<0.0001$ by ANOVA (a-d); ${ }^{*} p<0.05,{ }^{*} p<0.01, * * * p<0.001$ vs control (post hoc test)
At 12 months of age, plasma concentrations of glucose, insulin, cholesterol, NEFA and triacylglycerol were not significantly different between the two offspring groups (Table 2).

Offspring: OGTTs at 3 months of age In males, no difference in fasting plasma glucose and insulin concentrations was observed amongst the groups. An increase of the AUC for glucose showed marginal significance $(p=0.055)$. In females, no difference in basal glucose and insulin was observed among the groups. Glucose and insulin responses of female offspring of obese dams were not significantly impaired when compared with control (Fig. 4).

Offspring: euglycaemic-hyperinsulinaemic clamps In 8- to 9-month-old female offspring of obese dams, overnight fasting plasma insulin concentration was not significantly increased compared with control offspring $(274.3 \pm 97.3$ vs $170.2 \pm 41.7 \mathrm{pmol} / \mathrm{l})$. At steady-state euglycaemia, no significant difference was observed between female offspring of both groups for GIR $(0.126 \pm 0.009$ vs $0.138 \pm$ $0.015 \mathrm{mmol} \mathrm{kg}^{-1} \mathrm{~min}^{-1}$ ) and plasma insulin concentration $(663.3 \pm 170.2$ vs $460.1 \pm 45.1 \mathrm{pmol} / \mathrm{l})$.

In 10- to 11-month-old males, overnight fasting plasma insulin was significantly increased in offspring of obese

Table 2 Plasma variables measured in fasted male and female offspring at 2 and 12 months of age

\begin{tabular}{|c|c|c|c|c|c|c|}
\hline \multirow[t]{2}{*}{ Variable } & \multicolumn{3}{|l|}{2 months } & \multicolumn{3}{|l|}{12 months } \\
\hline & $\begin{array}{l}\text { Control } \\
\text { (Male } n=15 \\
\text { female } n=15 \text { ) }\end{array}$ & $\begin{array}{l}\text { Obese } \\
\text { (Male } n=13 \\
\text { female } n=12 \text { ) }\end{array}$ & Diet effect $p$ value & $\begin{array}{l}\text { Control } \\
\text { (Male } n=10 \\
\text { female } n=8 \text { ) }\end{array}$ & $\begin{array}{l}\text { Obese } \\
\text { (Male } n=9 ; \\
\text { female } n=8 \text { ) }\end{array}$ & Diet effect $p$ value \\
\hline \multicolumn{7}{|c|}{ Glucose (mmol/l) } \\
\hline Male & $6.8 \pm 0.1$ & $6.5 \pm 0.2$ & NS & $6.4 \pm 0.2$ & $6.3 \pm 0.3$ & NS \\
\hline Female & $6.7 \pm 0.2$ & $6.3 \pm 0.3$ & NS & $6.6 \pm 0.3$ & $6.3 \pm 0.3$ & NS \\
\hline \multicolumn{7}{|c|}{ Insulin (pmol/1) } \\
\hline Male & $119.8 \pm 19.1$ & $95.5 \pm 17.4$ & NS & $114.6 \pm 19.1$ & $142.8 \pm 34.7$ & NS \\
\hline Female & $145.8 \pm 19.1$ & $97.2 \pm 19.1$ & NS & $107.65 \pm 13.9$ & $137.2 \pm 15.6$ & NS \\
\hline \multicolumn{7}{|c|}{ Total cholesterol (mmol/l) } \\
\hline Male & $1.27 \pm 0.08$ & $1.14 \pm 0.10$ & NS & $1.32 \pm 0.10$ & $1.34 \pm 0.07$ & NS \\
\hline Female & $1.36 \pm 0.10$ & $1.19 \pm 0.09$ & NS & $1.38 \pm 0.15$ & $1.30 \pm 0.10$ & NS \\
\hline \multicolumn{7}{|c|}{ NEFA (mmol/l) } \\
\hline Male & $0.66 \pm 0.06$ & $0.98 \pm 0.08$ & 0.002 & $0.54 \pm 0.05$ & $0.56 \pm 0.03$ & NS \\
\hline Female & $0.63 \pm 0.06$ & $0.90 \pm 0.09$ & 0.019 & $0.54 \pm 0.08$ & $0.54 \pm 0.06$ & NS \\
\hline \multicolumn{7}{|c|}{ Triacylglycerol (mmol/l) } \\
\hline Male & $0.84 \pm 0.12$ & $0.88 \pm 0.08$ & NS & $0.88 \pm 0.16$ & $0.90 \pm 0.08$ & NS \\
\hline Female & $0.71 \pm 0.06$ & $0.79 \pm 0.07$ & NS & $1.05 \pm 0.18$ & $0.91 \pm 0.11$ & NS \\
\hline \multicolumn{7}{|c|}{ Leptin $(\mathrm{pg} / \mathrm{ml})$} \\
\hline Male & $2,793 \pm 304$ & $3,898 \pm 448$ & 0.038 & $5,338 \pm 484$ & $5,515 \pm 905$ & NS \\
\hline Female & $3,052 \pm 407$ & $3,857 \pm 401$ & NS & $6,364 \pm 842$ & $5,749 \pm 1,380$ & NS \\
\hline
\end{tabular}

Values are expressed as means \pm SEM 

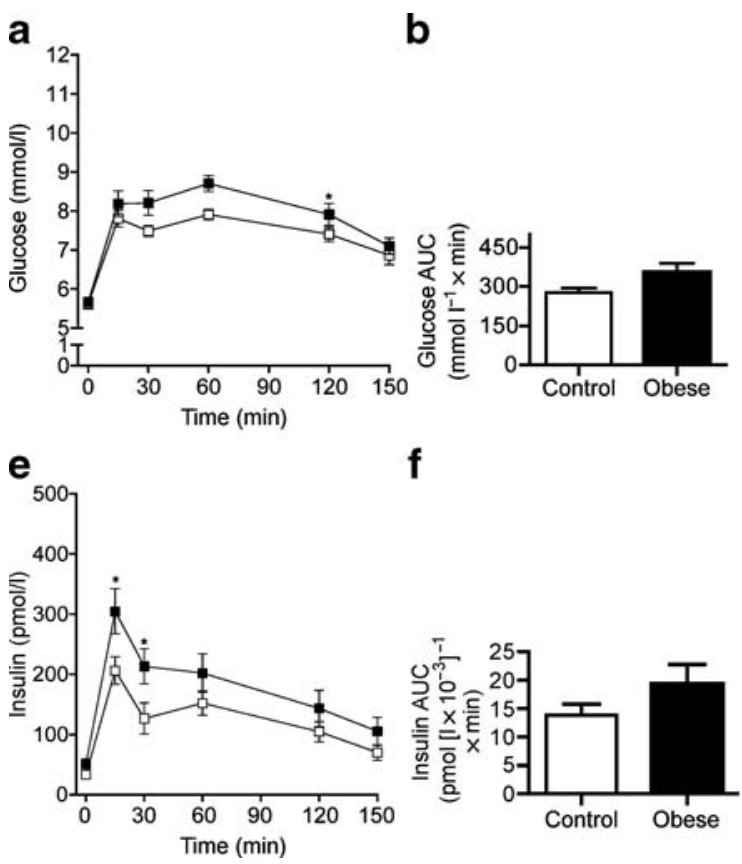

Fig. 4 Plasma glucose $(\mathbf{a}-\mathbf{d})$ and insulin $(\mathbf{e}-\mathbf{h})$ response after an OGTT performed in 3-month-old male (a, b, e, f) (control: white squares, $n=$ 10; obese: black squares, $n=8)$ and 3-month-old female $(\mathbf{c}, \mathbf{d}, \mathbf{g}, \mathbf{h})$ offspring (control: white circles, $n=8$; obese: black circles, $n=8$ ). The

dams compared with control $(421.9 \pm 114.6$ vs $151.1 \pm$ $38.6 \mathrm{pmol} / 1, p<0.05)$. At steady-state euglycaemia, GIR was decreased $(\sim 29 \%)$ in male offspring of obese dams compared with control $\left(0.135 \pm 0.003\right.$ vs $0.175 \pm 0.017 \mathrm{mmol} \mathrm{kg}^{-1} \mathrm{~min}^{-1}$, $p<0.05)$. The plasma insulin concentration measured at euglycaemia was also increased in male offspring of that group compared with control $(1423.7 \pm 229.2$ vs $791.8 \pm$ $76.4 \mathrm{pmol} / \mathrm{l}, p<0.05)$.

Offspring: pancreatic insulin content at 12 months of age At 12 months of age, the pancreatic insulin content was not significantly different between male offspring in the obese and control dams $(30.6 \pm 4.9$ vs $35.1 \pm 5.8 \mathrm{pmol} / \mathrm{mg}$ tissue weight) or between the respective female offspring groups ( $23.4 \pm 5.0 \mathrm{vs} 31.3 \pm 2.0 \mathrm{pmol} / \mathrm{mg}$ tissue weight).

Offspring: body composition at 12 months of age Male and female offspring of obese dams showed a twofold increase in fat pad mass compared with control. Females, but not males, of the same group showed a significant increase in weight of the adrenals, heart and kidneys (Table 3).

\section{Discussion}

This study has shown that male and to a lesser extent female offspring of dams rendered obese by long-term
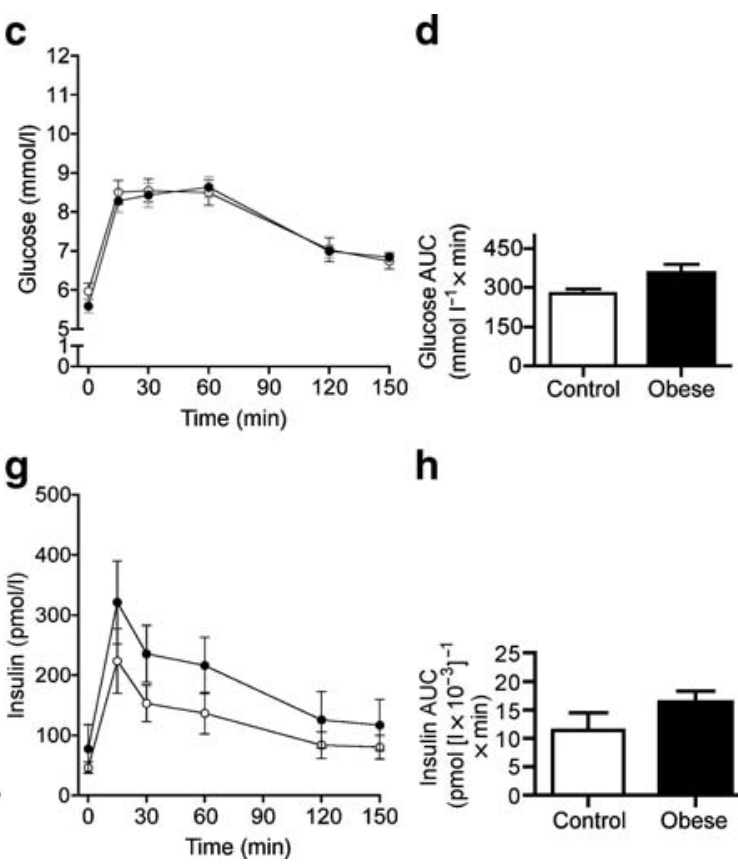

h

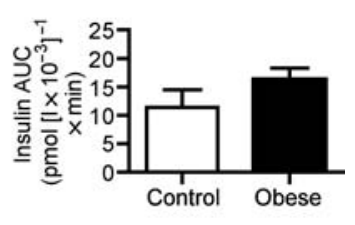

respective incremental AUCs of glucose (b, d) and insulin (f, h) are also shown. Results are expressed as mean \pm SEM. $p=0.0266$ (a, b), $p<$ $0.0001(\mathbf{c}, \mathbf{d}), p=0.0575(\mathbf{e}, \mathbf{f}), p=0.2777(\mathbf{g}, \mathbf{h})$ by ANOVA; ${ }^{*} p<0.05$ vs control (post hoc test)

high-energy feeding developed a metabolic syndrome-like phenotype characterised by increased adiposity and insulin resistance. Sex-related differences were observed, with male offspring more prone to develop precocious alterations of glucose homeostasis than females.

The concept of developmental programming, first proposed by Barker and colleagues in the 1990s [23], has been extensively demonstrated in human and animal studies focusing on the effects of maternal malnutrition [7]. Westernised societies are now confronted not with maternal undernutrition, but with an epidemic of obesity. Relatively little is known about the persistent consequences of maternal obesity for the developing offspring. Some studies in rodents have assessed influences of maternal high-energy diets using only a short time window, generally less than 14 days prior to mating or only during gestation and/or lactation, and have generally failed to achieve obesity in the dam $[16,19,20,24-26]$. A few, using a prolonged feeding period to induce obesity $[17,27,28]$, have generally switched from a high-energy diet to a control diet postdelivery [28], potentially inducing changes of the milk composition [29]. Since lactation may be a critical period for neonates in the programming of obesity, these protocols may affect the offspring phenotype [30]. Moreover, many studies used a high-fat diet without added sugar, which does not induce obesity in rodents unless fed for extensive periods [28]. In our model, approximately $11 \%$ of energy was provided by saturated fat and $43 \%$ from simple sugars, 
Table 3 Body composition of male and female offspring at 12 months of age

\begin{tabular}{|c|c|c|c|c|c|c|}
\hline \multirow[t]{2}{*}{ Variable } & \multicolumn{3}{|l|}{ Male } & \multicolumn{3}{|l|}{ Female } \\
\hline & Control $(n=5)$ & Obese $(n=6)$ & Diet effect $p$ value & Control $(n=4)$ & Obese $(n=5)$ & Diet effect $p$ value \\
\hline Body weight (g) & $502 \pm 29$ & $612 \pm 3$ & 0.032 & $300 \pm 9$ & $372 \pm 17$ & 0.013 \\
\hline Pancreas (g) & $0.157 \pm 0.011$ & $0.173 \pm 0.008$ & NS & $0.139 \pm 0.021$ & $0.130 \pm 0.003$ & NS \\
\hline Adrenals (g) & $0.058 \pm 0.004$ & $0.061 \pm 0.004$ & NS & $0.067 \pm 0.004$ & $0.085 \pm 0.003$ & 0.017 \\
\hline Liver (g) & $11.2 \pm 0.6$ & $12.6 \pm 0.6$ & NS & $8.0 \pm 0.7$ & $9.3 \pm 0.7$ & NS \\
\hline Heart (g) & $1.6 \pm 0.1$ & $1.9 \pm 0.1$ & NS & $1.0 \pm 0.1$ & $1.3 \pm 0.1$ & 0.010 \\
\hline Kidneys (g) & $3.4 \pm 0.1$ & $3.6 \pm 0.2$ & NS & $2.2 \pm 0.1$ & $2.6 \pm 0.1$ & 0.030 \\
\hline Brain (g) & $2.3 \pm 0.1$ & $2.3 \pm 0.1$ & NS & $2.0 \pm 0.1$ & $2.1 \pm 0.1$ & NS \\
\hline Soleus muscle (g) & $0.230 \pm 0.015$ & $0.231 \pm 0.15$ & NS & $0.140 \pm 0.012$ & $0.145 \pm 0.003$ & NS \\
\hline Mesenteric WAT (g) & $4.5 \pm 1.0$ & $8.6 \pm 1.6$ & $(0.073)$ & $5.8 \pm 0.4$ & $9.0 \pm 1.1$ & 0.040 \\
\hline Perigonadal WAT (g) & $6.6 \pm 0.7$ & $10.9 \pm 1.6$ & 0.049 & $8.4 \pm 0.8$ & $13.6 \pm 1.6$ & $(0.055)$ \\
\hline Perirenal WAT (g) & $5.8 \pm 1.0$ & $13.1 \pm 2.5$ & 0.031 & $3.6 \pm 0.3$ & $7.3 \pm 1.3$ & 0.046 \\
\hline Subcutaneous WAT (g) & $6.3 \pm 0.9$ & $12.1 \pm 2.0$ & 0.033 & $3.6 \pm 0.5$ & $7.7 \pm 1.6$ & $(0.063)$ \\
\hline Total WAT (g) & $23.3 \pm 3.4$ & $44.8 \pm 7.2$ & 0.034 & $21.4 \pm 1.4$ & $37.7 \pm 5.7$ & 0.042 \\
\hline
\end{tabular}

Values are expressed as means \pm SEM

WAT, white adipose tissue

$p$ values between parentheses almost reach significance

equivalent to high value within the normal dietary range in man, and hence reflective of human diet and obesity [31].

A direct effect of maternal obesity as such on the development of key features of metabolic syndrome in offspring has been suggested by studies in transgenic animals; adult wild-type progeny of obese and insulin-resistant heterozygous leptin receptor-deficient $\left(\mathrm{Lepr}^{\mathrm{db} /+}\right)$ mice showed an increase of fat mass [32, 33]. Using an identical diet to that of the present study, we have also recently shown a similar increase in fat mass in the offspring of obese mice, proving commonality of this model in different rodent species [34]. Further support for generation of obesity in the offspring of obese dams comes from Bayol et al., who showed that offspring of rats that were fed a 'junk food' diet (including highly palatable foods such as chocolate, crisps and doughnuts) in pregnancy and lactation developed increased fat mass after weaning on to a normal diet [35, 36]. In contrast to the present study, this was more predominant in females than males [35].

We cannot exclude a direct effect of elements of the obesogenic diet on the developing offspring. Indeed, the offspring of rats fed a fat-enriched diet during the gestation and/or lactation periods without development of overt maternal obesity also developed an increase in body fat mass [16, 37]. Male offspring of dams fed a diet enriched in saturated fatty acids (from 2 weeks prior to mating) showed a greater reduction in insulin sensitivity than offspring of dams on unsaturated fat diets [38], demonstrating the importance of the fatty acid composition of high-fat diets.
Indeed, the saturated fat component of the diet of the obese dams was high in the present study, although there was proportionately more carbohydrate than fat in the diet. With regard to a possible independent influence of the enriched carbohydrate element of the diet, less is known. Others [39] have shown that offspring of female rats fed a highcarbohydrate diet $(80 \%$ carbohydrate, $7 \%$ fat) for 3 weeks before mating, and during gestation and lactation did not show any increase in body fat at 15 weeks of age when compared with animals fed a diet high in saturated fats. When intragastric feeding ( $75 \%$ carbohydrate, $5 \%$ fat) for 3 weeks prior to pregnancy and during pregnancy was used to rapidly induce maternal obesity, offspring showed increased adiposity compared with controls, but only when both controls and experimental offspring were fed a highfat diet [28]. However, this protocol differed from that in the present study as the pups were cross-fostered to a control-fed dam. In view of these reports and given the composition of the diet used in the present study (11\% fat, $43 \%$ carbohydrates), it is likely that maternal body composition itself plays a major role on development of increased body mass in the offspring.

Insulin resistance is central to metabolic syndrome. Here, we have shown that male offspring of the obese dams were insulin-resistant, whereas there was no evidence for this in females at the age studied. This finding was suggested using OGTT and confirmed by the euglycaemic-hyperinsulinaemic clamp. While others have reported insulin resistance in normally fed offspring prenatally exposed to an obesogenic 
diet [28, 34] and in offspring of fat-fed dams [26], no previous study has used this 'gold standard' method to assess peripheral insulin resistance in offspring of obese dams. We have therefore provided unequivocal evidence that insulin resistance can be 'programmed' in offspring by diet-induced, maternal obesity in the rat.

The mechanisms underlying the development of insulin resistance remain to be determined, and future studies will ascertain whether this is a primary effect, for example through persistent alteration of insulin signalling pathways, or whether it is related to the development of adiposity in the offspring. In our 3-month-old males, which already showed evidence of impaired glucose tolerance, plasma concentrations of NEFA were raised (measured at 2 months). As NEFA are the product of adipose tissue lipolysis and in the obese state have been strongly implicated in the pathogenesis of peripheral insulin resistance, they could play a causative role [40].

The greater food intake in the offspring of the obese dams, which was evident from 10 weeks of age, may play a role in influencing the increased fat mass observed in the adult offspring. Since we have also observed hyperphagia in the offspring of obese mice fed the same diet [34], persistent alteration in regulation of appetite-controlling pathways may play a causative role in the development of increased adiposity in both species. Food intake has not been rigorously assessed by others addressing the same hypothesis [28], although Bayol et al. [35, 41] have implicated altered food preference (for 'junk food' over standard chow) in development of obesity in offspring of dams fed the 'junk food' diet throughout pregnancy and lactation, but not when exposed to the diet during pregnancy only. Similarly no difference was shown in food intake in the offspring of obese dams exposed to this obesogenic diet during gestation alone [28].

The suggestion that appetite could be developmentally regulated is supported by a growing body of evidence. Mechanistically, insulin, glucose and leptin have been implicated in the developmental programming of appetite in other models. In the present study, the pregnant dams (days 10-11) showed clear hyperinsulinaemia and hyperglycaemia, suggesting a phenotype similar to human gestational diabetes. Ideally, plasma analytes should have been assessed on the same day rather than over a 2 day period (days 10-11), but this is unlikely to have had a major influence on data interpretation. Moreover, adult offspring from a murine model of gestational diabetes (heterozygous C57BL/KsJLepr $^{d b /+}$ ) [32] and from a rat model of diabetes induced by streptozotocin [42] showed hyperphagia, increased adiposity and alterations of the glucose homeostasis.

There is now an increasing focus on the lactation period, which is recognised as a crucial 'window' for the programming of appetite in later life [8]. Plagemann's group has shown litter size reduction (and resultant overfeeding in neonatal life) promotes offspring hyperphagia and obesity in adult life [30]. Although litter size was standardised in the present study, enrichment of the milk composition would be anticipated to have a similar effect to small litter rearing. Leptin plays a major role in the control of appetite [43] and elegant studies have shown that this peptide can influence the development of neuronal projections between arcuate and paraventricular nuclei of the neonatal hypothalamus, thereby influencing appetite regulatory pathways [44, 45]. It has therefore been proposed that altered leptin exposure during neonatal life could induce leptin resistance, promoting hyperphagia and obesity $[8,46]$. To address this hypothesis, further studies should rigorously assess the postnatal leptin profile in milk composition, as well as the neonatal leptin profile in this model. Although not undertaken in the present study, weight and leptin profiles should preferably be assessed separately in male and female pups in view of the marked sex-related differences observed in adult offspring.

To our knowledge this study is the first to demonstrate differing degrees of insulin resistance between male and female offspring of obese rats. Sex-related differences are commonly described in other models although no mechanism has been identified [47, 48]. However, the design of our study in this regard was not ideal, as, for practical reasons, female offspring were studied at a younger age (8-9 months) than the males (10-11) months. While we cannot categorically state that the difference in age did not contribute to the sex-related difference observed in insulin resistance, our recent report on the offspring of obese mice [42] also showed that glucose intolerance was predominantly observed in males. Moreover, we have also previously shown a male predominance of insulin resistance in adult offspring of rats fed a lard-rich diet [49]. Also, there was a marginally significant difference in insulin resistance in males, but not in females at 3 months. Nonetheless, the relationship between the abnormalities observed and the normal processes of ageing, which we shall be exploring next, could provide interesting insights into premature development of age-related diseases, especially diabetes.

The increased litter size in the obese pregnancies was of interest and to our knowledge not previously reported. The associated reduction in pup size was small and there was no evidence of catch-up growth in the restricted litters followed longitudinally. Numerous studies have shown that fetal growth restriction is associated with a greater risk of insulin resistance and obesity in later life, and we cannot discount a persistent effect of modest fetal growth restriction relative to controls in this study. However, in the absence of rapid catch-up growth, as observed in severely growth-restricted pups from undernourished dams, it seems unlikely that this plays an important role in elaboration of the phenotype [50].

In conclusion, we have shown that obesity in female rats, manifested to a degree that in humans would translate into a 
clinically obese BMI, leads to a state of insulin resistance in male offspring and development of increased adiposity in offspring of both sexes. We propose that a developmentally acquired increase in food intake plays an important role in fat accumulation. Further studies using cross-fostering protocols will determine the relative influences of maternal diet-induced obesity during gestational and post partum periods, as well as addressing the role of the postnatal leptin status. Studies in man should not only address associations between maternal body and offspring body composition, but also relationships with offspring appetite.

Acknowledgements We thank M. T Ahn, W. Marteau, P. Beekhof and J. Cremers for their technical assistance. This work was supported by a grant from the European project EARNEST (Food-CT-2005-007036, 6th Frame Programme) and the Fonds de soutien Marguerite-Marie Delacroix. L. Poston is funded by Tommy's Charity, UK.

Duality of interest The authors declare that there is no duality of interest associated with this manuscript.

\section{References}

1. Alberti KG, Zimmet P, Shaw J, Group IETFC (2005) The metabolic syndrome-a new worldwide definition. Lancet 366:1059-1062

2. Wong ND (2007) Metabolic syndrome: cardiovascular risk assessment and management. Am J Cardiovasc Drugs 7:259-272

3. Grundy SM (2008) Metabolic syndrome pandemic. Arterioscler Thromb Vasc Biol 28:629-636

4. Nathan BM, Moran A (2008) Metabolic complications of obesity in childhood and adolescence: more than just diabetes. Curr Opin Endocrinol Diabetes Obes 15:21-29

5. Eckel RH, Grundy SM, Zimmet PZ (2005) The metabolic syndrome. Lancet 365:1415-1428

6. McMillen IC, Robinson JS (2005) Developmental origins of the metabolic syndrome: prediction, plasticity, and programming. Physiol Rev 85:571-633

7. Remacle C, Reusens B, Kalbe L et al (2001) Early malnutrition and programming of adult degenerative diseases: experimental, epidemiological and preventive studies. Nutr Metab Cardiovasc Dis 11:99-102

8. Taylor PD, Poston L (2007) Developmental programming of obesity in mammals. Exp Physiol 92:287-298

9. Boney CM, Verma A, Tucker R, Vohr BR (2005) Metabolic syndrome in childhood: association with birth weight, maternal obesity, and gestational diabetes mellitus. Pediatrics 115:e290-e296

10. Hull HR, Dinger MK, Knehans AW, Thompson DM, Fields DA (2008) Impact of maternal body mass index on neonate birthweight and body composition. Am J Obstet Gynecol 198(416): e411-e416

11. Sewell MF, Huston-Presley L, Super DM, Catalano P (2006) Increased neonatal fat mass, not lean body mass, is associated with maternal obesity. Am J Obstet Gynecol 195:1100-1103

12. Parsons TJ, Power C, Manor O (2001) Fetal and early life growth and body mass index from birth to early adulthood in 1958 British cohort: longitudinal study. BMJ 323:1331-1335

13. Lawlor DA, Timpson NJ, Harbord RM et al (2008) Exploring the developmental overnutrition hypothesis using parental-offspring associations and FTO as an instrumental variable. PLoS Med $5: \mathrm{e} 33$
14. Blair NJ, Thompson JM, Black PN et al (2007) Risk factors for obesity in 7-year-old European children: the Auckland Birthweight Collaborative Study. Arch Dis Child 92:866-871

15. Hillier TA, Pedula KL, Schmidt MM, Mullen JA, Charles MA, Pettitt DJ (2007) Childhood obesity and metabolic imprinting: the ongoing effects of maternal hyperglycemia. Diabetes Care 30:2287-2292

16. Armitage JA, Taylor PD, Poston L (2005) Experimental models of developmental programming: consequences of exposure to an energy rich diet during development. J Physiol 565:3-8

17. Férézou-Viala J, Roy AF, Sérougne C et al (2007) Long-term consequences of maternal high-fat feeding on hypothalamic leptin sensitivity and diet-induced obesity in the offspring. Am J Physiol Regul Integr Comp Physiol 293:R1056-R1062

18. Gorski JN, Dunn-Meynell AA, Hartman TG, Levin BE (2006) Postnatal environment overrides genetic and prenatal factors influencing offspring obesity and insulin resistance. Am J Physiol Regul Integr Comp Physiol 291:R768-R778

19. Guo F, Jen KL (1995) High-fat feeding during pregnancy and lactation affects offspring metabolism in rats. Physiol Behav 57:681-686

20. Khan IY, Dekou V, Douglas G et al (2005) A high-fat diet during rat pregnancy or suckling induces cardiovascular dysfunction in adult offspring. Am J Physiol Regul Integr Comp Physiol 288: R127-R133

21. Merezak S, Reusens B, Renard A et al (2004) Effect of maternal low-protein diet and taurine on the vulnerability of adult Wistar rat islets to cytokines. Diabetologia 47:669-675

22. Perrin D, Soulage C, Pequignot JM, Géloën A (2003) Resistance to obesity in Lou/C rats prevents ageing-associated metabolic alterations. Diabetologia 46:1489-1496

23. Barker DJ (1995) Intrauterine programming of adult disease. Mol Med Today 1:418-423

24. Aalinkeel R, Srinivasan M, Song F, Patel MS (2001) Programming into adulthood of islet adaptations induced by early nutritional intervention in the rat. Am J Physiol Endocrinol Metab 281:E640-E648

25. Khan I, Dekou V, Hanson M, Poston L, Taylor P (2004) Predictive adaptive responses to maternal high-fat diet prevent endothelial dysfunction but not hypertension in adult rat offspring. Circulation 110:1097-1102

26. Taylor PD, McConnell J, Khan IY et al (2005) Impaired glucose homeostasis and mitochondrial abnormalities in offspring of rats fed a fat-rich diet in pregnancy. Am J Physiol Regul Integr Comp Physiol 288:R134-R139

27. Holemans K, Caluwaerts S, Poston L, van Assche FA (2004) Dietinduced obesity in the rat: a model for gestational diabetes mellitus. Am J Obstet Gynecol 190:858-865

28. Shankar K, Harrell A, Liu X, Gilchrist JM, Ronis MJ, Badger TM (2008) Maternal obesity at conception programs obesity in the offspring. Am J Physiol Regul Integr Comp Physiol 294:R528R538

29. Rolls BA, Gurr MI, van Duijvenvoorde PM, Rolls BJ, Rowe EA (1986) Lactation in lean and obese rats: effect of cafeteria feeding and of dietary obesity on milk composition. Physiol Behav 38: $185-190$

30. Plagemann A (2006) Perinatal nutrition and hormone-dependent programming of food intake. Horm Res 65(Suppl 3):83-89

31. Henderson L, Gregory J, Irving K, Swan G (2003) The National Diet and Nutrition Survey: Adults aged 19 to 64 years, vol. 2: Energy protein carbohydrate fat and alcohol intake. TSO, London

32. Yamashita H, Shao J, Qiao L, Pagliassotti M, Friedman JE (2003) Effect of spontaneous gestational diabetes on fetal and postnatal hepatic insulin resistance in Lepr(db/+) mice. Pediatr Res 53:411-418

33. Lambin S, van Bree R, Caluwaerts S, Vercruysse L, Vergote I, Verhaeghe J (2007) Adipose tissue in offspring of Lepr(db/+) 
mice: early-life environment vs genotype. Am J Physiol Endocrinol Metab 292:E262-E271

34. Samuelsson AM, Matthews PA, Argenton M et al (2008) Dietinduced obesity in female mice leads to offspring hyperphagia, adiposity, hypertension, and insulin resistance: a novel murine model of developmental programming. Hypertension 51:383392

35. Bayol SA, Simbi BH, Bertrand JA, Stickland NC (2008) Offspring from mothers fed a "junk food" diet in pregnancy and lactation exhibit exacerbated adiposity which is more pronounced in females. J Physiol 586:3219-3230

36. Bayol SA, Simbi BH, Stickland NC (2005) A maternal cafeteria diet during gestation and lactation promotes adiposity and impairs skeletal muscle development and metabolism in rat offspring at weaning. J Physiol (Lond) 567:951-961

37. Buckley AJ, Keserü B, Briody J, Thompson M, Ozanne SE, Thompson CH (2005) Altered body composition and metabolism in the male offspring of high fat-fed rats. Metab Clin Exp 54: 500-507

38. Siemelink M, Verhoef A, Dormans JA, Span PN, Piersma AH (2002) Dietary fatty acid composition during pregnancy and lactation in the rat programs growth and glucose metabolism in the offspring. Diabetologia 45:1397-1403

39. Gregersen S, Dyrskog SE, Storlien LH, Hermansen K (2005) Comparison of a high saturated fat diet with a high carbohydrate diet during pregnancy and lactation: effects on insulin sensitivity in offspring of rats. Metab Clin Exp 54:1316-1322

40. Delarue J, Magnan C (2007) Free fatty acids and insulin resistance. Curr Opin Clin Nutr Metab Care 10:142-148
41. Bayol SA, Farrington SJ, Stickland NC (2007) A maternal 'junk food' diet in pregnancy and lactation promotes an exacerbated taste for 'junk food' and a greater propensity for obesity in rat offspring. Br J Nutr 98:843-851

42. Plagemann A, Harder T, Melchior K, Rake A, Rohde W, Dörner G (1999) Elevation of hypothalamic neuropeptide Y-neurons in adult offspring of diabetic mother rats. Neuroreport 10:3211-3216

43. Plagemann A, Harder $\mathrm{T}$ (2009) Hormonal programming in perinatal life: leptin and beyond. Br J Nutr 101:151-152

44. Bouret SG, Draper SJ, Simerly RB (2004) Formation of projection pathways from the arcuate nucleus of the hypothalamus to hypothalamic regions implicated in the neural control of feeding behavior in mice. J Neurosci 24:2797-2805

45. Bouret SG (2008) Crossing the border: developmental regulation of leptin transport to the brain. Endocrinology 149:875-876

46. Ladyman SR (2008) Leptin resistance during pregnancy in the rat. J Neuroendocrinol 20:269-277

47. Sugden MC, Holness MJ (2002) Gender-specific programming of insulin secretion and action. J Endocrinol 175:757-767

48. Zambrano E, Bautista CJ, Deás M et al (2006) A low maternal protein diet during pregnancy and lactation has sex- and window of exposure-specific effects on offspring growth and food intake, glucose metabolism and serum leptin in the rat. J Physiol (Lond) 571:221-230

49. Khan IY, Taylor PD, Dekou V et al (2003) Gender-linked hypertension in offspring of lard-fed pregnant rats. Hypertension 41:168-175

50. Hales CN, Ozanne SE (2003) The dangerous road of catch-up growth. J Physiol (Lond) 547:5-10 